\title{
Industrial excess heat use: Systems analysis and CO2 emissions reduction
}

\author{
Sarah Broberg Viklund and Magnus Karlsson
}

\section{Linköping University Post Print}

\section{Tweet}

N.B.: When citing this work, cite the original article.

Original Publication:

Sarah Broberg Viklund and Magnus Karlsson, Industrial excess heat use: Systems analysis and CO2 emissions reduction, 2015, Applied Energy, (152), 189-197.

http://dx.doi.org/10.1016/j.apenergy.2014.12.023

Copyright: Elsevier

http://www.elsevier.com/

Postprint available at: Linköping University Electronic Press

http://urn.kb.se/resolve?urn=urn:nbn:se:liu:diva-120206 


\title{
Industrial excess heat use: Systems analysis and $\mathrm{CO}_{2}$ emissions reduction
}

\author{
Sarah Broberg Viklund*, Magnus Karlsson \\ Department of Management and Engineering, Division of Energy Systems, Linköping \\ University, SE-581 83 Linköping, Sweden.
}

*Corresponding author: Tel.: +46 13 281103. E-mail address: sarah.broberg.viklund@liu.se

\begin{abstract}
The adopted energy efficiency directive stresses the use of excess heat as a way to reach the EU target of primary energy use. Use of industrial excess heat may result in decreased energy demand, $\mathrm{CO}_{2}$ emissions reduction, and economic gains. In this study, an energy systems analysis is performed with the aim of investigating how excess heat should be used, and the impact on $\mathrm{CO}_{2}$ emissions. The manner in which the heat is recovered will affect the system. The influence of excess heat recovery and the trade-off between heat recovery for heating or cooling applications and electricity production has been investigated using the energy systems modeling tool reMIND. The model has been optimized by minimizing the system cost. The results show that it is favorable to recover the available excess heat in all the investigated energy market scenarios, and that heat driven electricity production is not a part of the optimal solution. The trade-off between use of recovered excess heat in the heating or cooling system depends on the energy market prices and the type of heat production. The introduction of excess heat reduces the $\mathrm{CO}_{2}$ emissions in the system for all the studied energy market scenarios.
\end{abstract}

Keywords: excess heat, waste heat, energy systems modeling, $\mathrm{CO}_{2}$ emission reduction, heat recovery

\section{NOMENCLATURE}

\section{Abbreviation}

$\begin{array}{ll}\text { HOB } & \text { Heat-only boilers } \\ \text { CHP } & \text { Combined heat and power } \\ \text { COP } & \text { Coefficient of performance } \\ \text { DC } & \text { District cooling } \\ \text { DH } & \text { District heating } \\ \text { EED } & \text { Energy Efficiency Directive } \\ \text { EMS } & \text { Energy market scenario } \\ \text { ENPAC } & \text { Energy Price and Carbon Balance Scenarios } \\ \text { EU } & \text { European Union } \\ \text { FT } & \text { Fischer Tropsch diesel } \\ \text { GHG } & \text { Greenhouse gases } \\ \text { IO } & \text { Investment Opportunity } \\ \text { MILP } & \text { Mixed Integer Linear Programming } \\ \text { NG } & \text { Natural gas } \\ \text { NGCC } & \text { Natural gas combined cycle plant } \\ \text { ORC } & \text { Organic Rankine cycle }\end{array}$




\section{INTRODUCTION}

In the work to counteract the unsustainable use of the world's resources and climate change, the European Union (EU) launched the "20-20-20 objectives" in 2008. One of the EU targets is to reduce the use of primary energy with $20 \%$ coming through energy efficiency measures. [1] The adopted Energy Efficiency Directive (EED) raises the importance of using excess heat as a way to reach the EU target [2]. Efficient use of resources can reduce the use of primary energy and reduce the emissions of greenhouse gases (GHG); and one way to achieve this could be through the use of available industrial excess heat.

The use of industrial excess heat can be seen as a well-established concept and has been implemented in several industries and societies. Efficient use of resources can be from both internal and external improvements, and there are several options for utilization of these unused heat resources [3-6]. It is important to first reduce the amount of excess heat from industrial processes. Then, heat recovery can be done in the processes in which it arose, used for other internal applications, or for external use. Excess heat can either be recovered for heating applications (e.g., delivered as district heating), or the energy can be used for generating electricity. The use of excess heat may result in decreased energy demand, reduced $\mathrm{CO}_{2}$ emissions and economic gains and, furthermore, improved energy efficiency resulting from excess heat recovery is attractive from a resource use perspective. [7]

A number of district heating (DH) systems in Sweden accept industrial excess heat as a part of their fuel mix and in 2011 excess heat accounted for $7.2 \%$ of the heat deliveries in the Swedish DH networks [8; 9]. Several research studies investigate excess heat recovery (both thermal applications and heat driven electricity generation) and heat storage technologies [1018]. Johansson and Söderström [13] compare and evaluate heat driven electricity generation technologies for recovery of low-temperature industrial excess heat based on heat source temperature, efficiency, capacity, economy and potential electricity production. The study indicates that investments in heat driven electricity generation technologies could be profitable, however not all associated costs are included in the study. [13] Campana et al. [11] estimates the potential power output from excess heat driven Organic Rankine cycle (ORC) in the cement, steel, glass and oil and gas industry in 27 European countries. The authors conclude ORC to be a viable option for heat recovery and estimate the potential electricity generation from ORC to approximately 21.6 TWh per year. [11] Persson and Werner [16] studies recovered excess heat in the DH system in the EU27 to reduce primary energy demand and identify a great potential for increased excess heat use if applying best member state practices. Ammar et al. [10] discusses low-grade heat recovery and the authors bring forward the importance of a holistic view to increase the number of opportunities to reduce the environmental impact by heat recovery.

\section{AIM AND IMPLEMENTATION}

Several research studies present benefits of heat recovery, but even though there are examples of use of industrial excess heat, studies show that there are still large untapped potentials [19; 20]. The importance of a holistic view is raised in Ammar et al. [10] and hence, there is a need for system studies within the field of excess heat use. The overall aim of this paper is to perform an energy systems analysis in order to recognize implications of future heat recovery (e.g. district heating deliveries) and electricity generation (e.g. through ORC) from industrial excess heat. A large number of factors (e.g. what the heat replaces) influence how the system is affected and several different factors have therefore been analyzed by using consistent energy market scenarios. The optimization tool, reMIND [21], is used to minimize the system cost for the different factors that are altered. By using this method, the changes occurring in 
the energy system and its boundary conditions can be analyzed. The optimization tool used in this study minimizes the system cost and finds the optimal system solution for excess heat recovery (based on the given assumptions) from a large number of variable factors.

The aim of this study has been to investigate how available industrial excess heat should be used to reduce system cost. The aim has also been to study the effects on $\mathrm{CO}_{2}$ emissions due to excess heat use. The aim of this study is not to present the overall system cost, and therefore only costs that differ between the studied scenarios will be included in the model. Use of excess heat will require different types of investments (e.g. in infrastructure and technology) and the investment opportunity will be calculated and presented. The results presented in this study are based on one studied case, but the results presented in this paper contribute to the understanding of excess heat use in general. The results may be used as a part of a decision basis for heat recovery investments or when developing strategies for climate change mitigation in general.

\section{METHOD}

\subsection{CASE STUDY}

A case study was conducted to investigate the implications of industrial excess heat use. The energy system and the consequences for excess heat use were studied using energy systems modeling. This study is based on a study presented in Broberg Viklund and Johansson [3] where a questionnaire was sent to producing companies classified as firms holding high environmental impact (according to the classification in [22]) in Gävleborg County, Sweden in spring of 2012 [3]. The energy use in Gävleborg County adds up to approximately $20 \mathrm{TWh}$ (in 2011) [23], which results in direct $\mathrm{CO}_{2}$ emissions totaled approximately 1580 kton [24]. The county holds a large share of energy intensive industry (e.g. pulp and paper, and steel industries) and the annual use of energy in the county within this sector (2011) adds up to approximately $11.3^{1} \mathrm{TWh}$ [23]. The firms answering the questionnaire reported a total untapped industrial excess heat potential of approximately $0.8 \mathrm{TWh} /$ year corresponding to $8.4 \%$ of the energy input among the firms that completed the questionnaire. The heat could be found in different energy carriers (water, flue gases, air and heat in materials) and the temperature of the heat ranged from $45-1600^{\circ} \mathrm{C}$. [3] The manner in which the excess heat is used will affect the system, e.g. the $\mathrm{CO}_{2}$ emissions. Though the purpose is not to fully reflect this county, the study is based on the industrial excess heat potential in water, flue gases, and air in Gävleborg County as presented in [3], and summarized in Table 1. However, it is assumed in this study that the potential is the actual potential available at the point of use for the heat use technologies in this study, that is, the recovered heat that has been exchanged to a suitable medium.

Table 1 Industrial excess heat potential (approximate numbers) modeled. The heat potential is derived from a questionnaire in Gävleborg County presented in Broberg Viklund and Johansson [3].

\begin{tabular}{|l|l|l|l|}
\hline \multirow{2}{*}{$\begin{array}{l}\text { Temperature } \\
\left({ }^{\circ} \mathbf{C}\right)\end{array}$} & \multicolumn{3}{|c|}{ Heat carrier $($ GWh/year $)$} \\
\cline { 2 - 4 } & Water & $\begin{array}{l}\text { Flue } \\
\text { gases }\end{array}$ & Air \\
\hline 45 & - & - & 0.00003 \\
\hline 50 & 150 & - & - \\
\hline 55 & 1 & - & - \\
\hline
\end{tabular}

\footnotetext{
${ }^{1}$ This figure includes electricity use in the construction sector.
} 


\begin{tabular}{|l|l|l|l|}
\hline 60 & 183 & - & 41 \\
\hline 65 & 82 & - & - \\
\hline 75 & - & 3 & - \\
\hline 95 & 2 & - & - \\
\hline 100 & 72 & - & - \\
\hline 165 & - & 98 & - \\
\hline 275 & - & 61 & - \\
\hline Not specified & 70 & 0.06 & - \\
\hline
\end{tabular}

\subsection{ENERGY SYSTEMS MODELING TOOL}

The studied system is modeled using the energy systems modeling tool reMIND ${ }^{2}$. The tool has been developed for optimization of dynamic industrial energy systems and uses mixed integer linear programming (MILP) to minimize system costs (system costs include e.g., energy costs and costs for raw materials). reMIND can be used for several purposes. For example, it can be used to find the optimal structure of an industrial energy system, and/or to find the optimal flow distribution in a fixed structure, and/or be used to investigate changes occurring in an industrial energy system or its boundary conditions.

The structure of the energy system is represented in a graphical interface as a network of nodes and branches. The branches represent flows of energy or materials while the nodes represent conversion processes of energy and materials. The number of nodes and branches depends on the complexity of the system.

Variations in the energy system such as energy prices or production processes during the optimization period can be represented in the model as a number of time steps. [21] The tool has been applied on several industries (e.g. pulp and paper, forest, automobile manufacturing and chemical) to study both economic and environmental aspects (e.g. $\mathrm{CO}_{2}$ emission impact) [25-28]. A more through description of the method can be found in [21].

The energy systems modeling tool reMIND minimizes the system cost and finds the optimal system solution for use of excess heat in this study. If using a simulation tool, instead of an optimization tool, feasible solutions may be found, but the global optimal solution may not be found, instead local optimal solutions are likely to be found.

\subsection{ENERGY MARKET PRICES AND $\mathrm{CO}_{2}$ EMISSIONS}

To evaluate the changes on $\mathrm{CO}_{2}$ emissions of use of industrial excess heat in the system studied, the model was optimized using six different future energy market scenarios (EMS-1 to EMS-6) for 2030. More robust results can be obtained by using consistent scenarios predicting possible cornerstones of the future energy market. The Energy Price and Carbon Balance Scenarios (ENPAC) tool version 1.8 was used to construct the scenarios; for a detailed description of the tool see references [29-30].

Input to the ENPAC tool were fossil fuel prices combined with assumed values for energy and climate mitigation policy instruments (hence input to the tool is fossil fuel prices and charges for emitting $\mathrm{CO}_{2}$ ). Based on the input to the tool, the probable marginal technologies for electricity production and the marginal user of biomass for each scenario can be determined, see Table 2. This yields consistent values for energy prices and corresponding $\mathrm{CO}_{2}$ emissions associated with the marginal use of the energy carriers. Input prices in the tool are taken from

\footnotetext{
${ }^{2}$ reMIND is publicly available tool and can be downloaded from: https://code.google.com/p/tremind/.
} 
the scenarios presented in World Energy Outlook 2011 [31]. In the evaluation of effects on $\mathrm{CO}_{2}$ emissions, biomass was considered a limited resource (i.e. sufficient biomass is not available to substitute for all fossil fuels in society) and a marginal electricity principle was used. According to the marginal electricity principle, changes in electricity use affect the electricity production with the highest operational cost at a given time. Hence, changes in electricity use (increase or decrease) would result in changes in marginal electricity production (increase or decrease) [32]. For a thorough discussion of the marginal electricity principle see [32-33]. When excess heat replaces energy originating from biomass, biomass will be released and used by the marginal user of biomass. In this paper, the electricity market is put in a European context while the heat market is put in a Swedish context. In addition, the size of the DH system likely affects the choice of heat production. A large DH system is more likely to use combined heat and power (CHP) plants in the heat production compared to smaller DH systems [34]. This study considers two potential systems: a DH system based on heat-only boilers (HOB) (mainly bio based HOB and a small share of coal-HOB, NG-HOB (natural gas-HOB), and oil-HOB), and a system based on CHP (mainly bio based CHP and bio based HOB and a small share of coal-CHP, NG-CHP, coal-HOB, NG-HOB, oil-HOB, and heat pump). An overview of the fuel mix in the Swedish DH system can be found in [23]. The energy market parameters for the different scenarios used in this study can be seen in Table 2 .

Table 2 An overview of the possible future energy market scenarios for 2030 modeled (EMS1 to EMS-6). FT=Fischer Tropsch diesel, NGCC=Natural gas combined cycle plant.

\begin{tabular}{|c|c|c|c|c|c|c|}
\hline EMS & $\mathbf{1}^{\mathrm{a}}$ & $2^{\mathbf{b}}$ & $3^{c}$ & $4^{a}$ & $5^{b}$ & $6^{c}$ \\
\hline $\begin{array}{l}\text { Marginal user of } \\
\text { biofuel }\end{array}$ & FT & FT & Coal & FT & FT & Coal \\
\hline $\begin{array}{l}\text { Build marginal } \\
\text { technology for } \\
\text { electricity } \\
\text { production }\end{array}$ & Coal & Coal & NGCC & Coal & Coal & NGCC \\
\hline $\begin{array}{l}\mathrm{CO}_{2} \text { effect from } \\
\text { marginal } \\
\text { electricity } \\
\text { production } \\
\left(\mathrm{kg} / \mathrm{MWh}_{\mathrm{el}}\right)\end{array}$ & 714 & 714 & 340 & 714 & 714 & 340 \\
\hline DH system & $\begin{array}{l}\text { Bio- } \\
\text { HOB }\end{array}$ & $\begin{array}{l}\text { Bio- } \\
\text { HOB }\end{array}$ & $\begin{array}{l}\text { Bio- } \\
\text { HOB }\end{array}$ & $\begin{array}{l}\text { Bio- } \\
\text { CHP }\end{array}$ & $\begin{array}{l}\text { Bio- } \\
\text { CHP }\end{array}$ & $\begin{array}{l}\text { Bio- } \\
\text { CHP }\end{array}$ \\
\hline $\begin{array}{l}\mathrm{CO}_{2} \text { emission } \\
\text { reduction if } \\
\text { industrial excess } \\
\text { heat is exported } \\
\text { to a DH system } \\
(\mathrm{kg} / \mathrm{MWh} \text { heat) }\end{array}$ & 150 & 150 & 363 & -20 & -20 & 351 \\
\hline \multicolumn{7}{|l|}{$\begin{array}{l}\text { Price } \\
(\text { EUR/MWhfuel/el })\end{array}$} \\
\hline $\begin{array}{l}\text { Electricity (incl. } \\
\mathrm{CO}_{2} \text { charge) }\end{array}$ & 68 & 67 & 86 & 68 & 67 & 86 \\
\hline Biomass & 38 & 33 & 41 & 38 & 33 & 41 \\
\hline $\begin{array}{l}\text { Coal (incl. } \mathrm{CO}_{2} \\
\text { charge) }\end{array}$ & 24 & 23 & 35 & 24 & 23 & 35 \\
\hline Natural gas (incl. & 48 & 46 & 49 & 48 & 46 & 49 \\
\hline
\end{tabular}




\begin{tabular}{|l|l|l|l|l|l|l|}
\hline $\mathrm{CO}_{2}$ charge) & & & & & & \\
\hline $\begin{array}{l}\text { Oil (incl. } \mathrm{CO}_{2} \\
\text { charge) }\end{array}$ & 83 & 74 & 75 & 83 & 74 & 75 \\
\hline $\begin{array}{l}\text { Coal (excl. } \mathrm{CO}_{2} \\
\text { charge) }\end{array}$ & 13 & 12 & 9 & 13 & 12 & 9 \\
\hline $\begin{array}{l}\text { Natural gas (excl. } \\
\mathrm{CO}_{2} \text { charge) }\end{array}$ & 41 & 39 & 33 & 41 & 39 & 33 \\
\hline
\end{tabular}

${ }^{\text {a }}$ Fuel prices on the world market: Oil 63 EUR/MWh, Natural gas 36 EUR/MWh, Coal 12 EUR/MWh, $\mathrm{CO}_{2}$ emission charge 30 EUR/tons. Derived from "Current policies scenario" in World Energy Outlook 2011 [31].

${ }^{\mathrm{b}}$ Fuel prices on the world market: Oil 55 EUR/MWh, Natural gas 34 EUR/MWh, Coal 11 EUR/MWh, $\mathrm{CO}_{2}$ emission charge 30 EUR/tons. Derived from "New policies scenario" in World Energy Outlook 2011 [31].

${ }^{\mathrm{c}}$ Fuel prices on the world market: Oil 46 EUR/MWh, Natural gas 28 EUR/MWh, Coal 7 EUR/MWh, $\mathrm{CO}_{2}$ emission charge 72 EUR/tons. Derived from “450 scenario" in World Energy Outlook 2011 [31].

\subsection{ECONOMIC EVALUATION}

The investment opportunity (IO) will be calculated for the six studied energy market scenarios. It can be calculated when it is difficult to estimate the total investment cost. Therefore, the economic evaluation in this study will be based on IO. Using IO for economic evaluation offers a way to estimate how high the unknown costs associated with the system change could be for the investment to be profitable. This is done through a comparison between the costs associated with the original system (in this case a system without excess heat use) and the system under discussion in this paper (a system with excess heat use). Thus, if the IO holds a positive value it represents the savings potential associated with that investment. IO has been used in several previous studies for economic evaluation for different processes [e.g. 35-37]. The IO in this paper is thus presented as the annual difference in energy costs between the systems with and without available excess heat. The annual system cost is calculated as:

$$
\mathrm{C}_{\text {system }}=\mathrm{C}_{\mathrm{el}}+\mathrm{C}_{\text {biomass }}+\mathrm{C}_{\text {coal }}+\mathrm{C}_{\mathrm{NG}}+\mathrm{C}_{\mathrm{oil}}-\mathrm{R}_{\mathrm{el}}
$$

where $\mathrm{C}_{\mathrm{el}}, \mathrm{C}_{\text {biomass, }} \mathrm{C}_{\text {coal }}, \mathrm{C}_{\mathrm{NG}}, \mathrm{C}_{\text {oil }}$ are the annual cost for electricity, coal, natural gas and oil and $\mathrm{R}_{\mathrm{el}}$ are the annual revenues for sold electricity produced within the system boundary. For each of the scenarios the annual investment opportunity is given by the difference in system cost between the system if excess heat is available and the system where it is not according to:

$$
\mathrm{IO}=\mathrm{C}_{\text {system excl. excess heat }}-\mathrm{C}_{\text {system incl. excess heat }}
$$

where $\mathrm{C}_{\text {system excl. excess heat }}$ is the annual system cost for the system if no excess heat is available and used and $\mathrm{C}_{\text {incl. excess heat }}$ is the annual system cost if the available excess heat is used. The total IO depends on the pay-back criteria for the investments. The actual investment as well as costs associated with that investment, such as operation and maintenance costs, needs to be covered with the IO.

\section{TECHNOLOGIES FOR EXCESS HEAT USE}

External use of industrial excess heat has been modeled and the system optimized in order to investigate the trade-off between different technologies for excess heat use. Three commercial options have been studied: recovered heat that is delivered to a district heating network, used for heat driven district cooling (DC), and used for electricity production through ORC. 
DH systems are used to for example supply buildings with heat from a collective heating system. The thermal energy can be obtained from different sources, industrial excess heat being one of them. Today, several DH grids in Sweden already accept excess heat [8]. Depending on for example the heat load demand, the water temperature in the DH system varies. The supply temperature ranges from $70-120^{\circ} \mathrm{C}$, and the return water temperature from 40-65 ${ }^{\circ}$ C. [38] Depending on the excess heat temperature, it can either be fed into the DH system directly or it must first be upgraded.

DC systems are used to for example supply office buildings with cooling and different technologies can be used for cooling production. In contrast to compression chillers that are driven with electricity, absorption chillers use heat in the cooling processes. Only a small proportion of electricity is needed for pumping (2\% of the produced cooling). [39] Absorption chillers are suitable for water-distributed cooling, and they have a coefficient of performance (COP) of about 0.7 [40] (compared to compression chillers which normally have a COP of 2 [26]).

Organic Rankine cycle: In the ORC, heat is used for electricity production. A working medium is heated and the expanded working medium passes a turbine and electricity is generated in a generator. The Rankine cycle uses water as a working medium and requires an excess heat source of $240^{\circ} \mathrm{C}$ or higher. The lower boiling point of the working medium in ORC (uses organic fluids as working medium) allows low-grade excess heat to be used $\left(>30^{\circ} \mathrm{C}\right)$. However, the efficiency depends on the temperature of the excess heat source and the temperature of the working medium. [41-43]

\section{MODEL DESCRIPTION}

The general structure of the model is displayed in Figure 1. The arrows represent possible flows in the model and the dashed line represents the system boundary. The system boundary is drawn so that the system includes the sources of excess heat presented in Table 1. As can be seen in Figure 1, the system boundary is drawn so that the studied system also includes the measures studied (DH, absorption chiller (DC) and ORC), and the alternative heat or electricity production technology used to cover the heating and cooling demand if the excess heat use technology is not implemented. The cooling demand will be covered with compression cooling, and the heat demand with boilers (EMS-1 to EMS-3), or CHP plants and boilers (EMS-4 to EMS-6). The units within the system also use electricity and may use fuels and may produce electricity. When optimizing the model, the optimal solution for excess heat use under the given circumstances is obtained. 


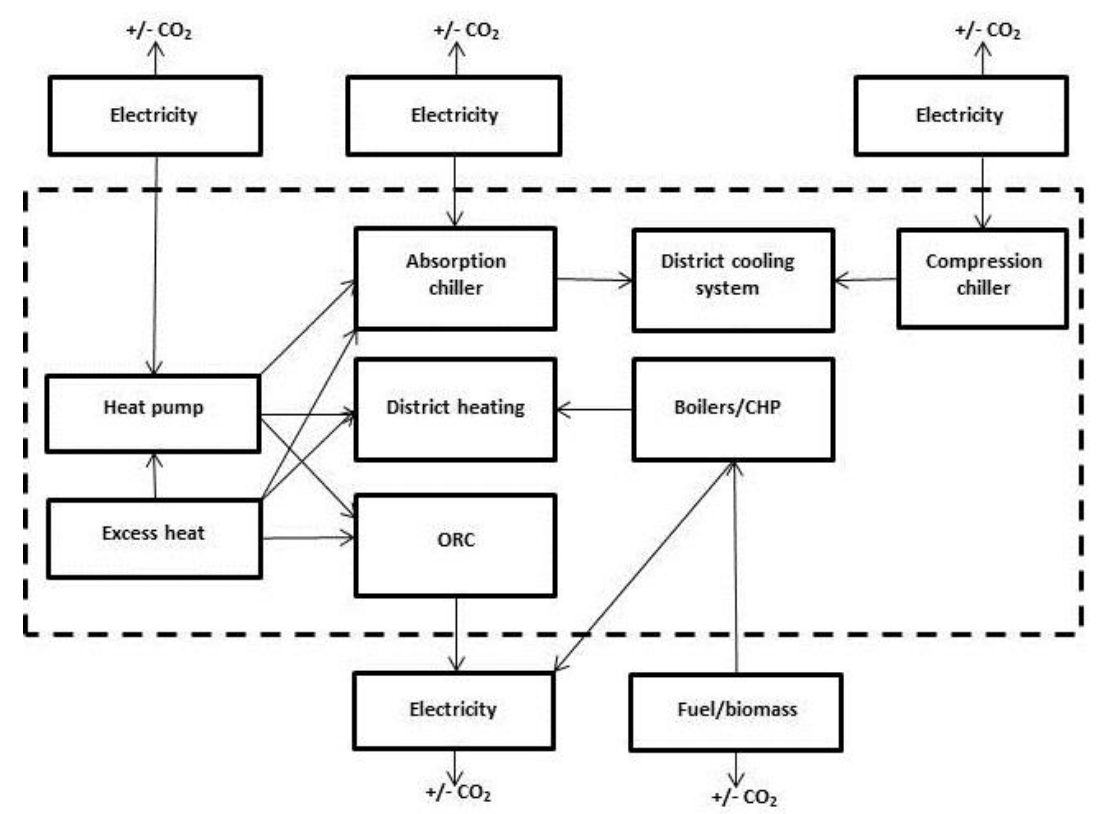

Figure 1 The general structure of the model. The dashed line represents the system boundary.

The excess heat in the system is assumed to be evenly distributed throughout the year and free of charge. The total power of excess heat is approximately $96 \mathrm{MW}_{\text {heat }}{ }^{3}$. The year is divided into three periods (according to Swedish seasons): T1 - autumn/spring (April, May, October, and November; 2674 hours); T2 - winter (January, February, March, and December; 2652 hours); and T3 - summer (June, July, August, and September; 2674 hours). The heat and cooling demand for the period T1 (autumn/spring) is set to the maximum power of the available excess heat. The heat demand for T2 (winter) and T3 (summer) is, based on T1 (autumn/spring) demand, recalculated using seasonal data trends from the regional heat market study [44]. In other words, the summer heat load is lower, and the winter heat load is higher than the autumn/spring load; this assumption follows the heat load data in the regional heat market study [44]. The cooling demand for winter and summer is calculated using the same factors, but on the contrary. The use of different heat and cooling loads allows studying differences between scenarios where there is no need for the full untapped potential and if the heat/cooling load is higher than the available excess heat. Due to the fixed heat and cooling demand in the three periods, the same amount of heat and cooling has to be produced in all the studied scenarios and hence the total cost for sold DH and DC will be the same in all studied scenarios. Since the DH and DC prices will not affect the model solution, these prices are not included in the model. The heat production follows the Swedish mix presented in the ENPAC tool [29; 30]. EMS-1, EMS-2 and EMS-3 represent a DH system based on mainly bio-HOB while EMS-4, EMS-5 and EMS-6 represent a DH system based on mainly bio-CHP and bio-HOB. It is assumed that the heat production mix is the same throughout the three periods due to monthly variations. Prices for fuels used in boilers include $\mathrm{CO}_{2}$ charge while prices for fuels used in CHP plants do not, according to the Swedish taxation system for heat deliveries to the industry [45].

To calculate the electricity price variations during the three periods, electricity price data (2012) from Nord Pool Spot was used [46]. A factor that describes the fluctuations over the given periods was calculated using this data. The electricity prices in the different scenarios

\footnotetext{
${ }^{3}$ Calculated from the excess heat potential presented in Table 1 and 8000 production hours.
} 
(see Table 2) were then recalculated for the three periods using this fluctuation factor. Autumn/spring is assumed to hold the electricity price listed in Table 2, winter holds a higher electricity price than autumn/spring (fluctuation factor: 1.2), and summer holds a lower electricity price than autumn/spring (fluctuation factor: 0.8 ). The same electricity prices are used for purchased electricity as for sold electricity produced in the ORC or CHP plants, where sold electricity reduces the system cost.

The model uses a temperature requirement of the heat source of $10^{\circ} \mathrm{C}$ above the technology specific temperature requirement (the technology specific temperature requirement for each technology can be found in Table 3), but heat pumps can be used to meet the requirements. If heat pumps are used, the temperature of the heat source will be pumped to $10^{\circ} \mathrm{C}$ above the lowest specific temperature requirement for each technology, and a theoretical COP value is used. Technical data regarding the boilers and CHP plants in the DH system is derived from the ENPAC tool $[29 ; 30]$ and can also be found in Table 3.

Table 3 Input data to the model.

\begin{tabular}{|l|l|l|}
\hline Model input & Number & Reference \\
\hline $\begin{array}{l}\text { Temperature } \\
\text { requirement DH }\end{array}$ & $90^{\circ} \mathrm{C}$ & {$[38]$} \\
\hline $\begin{array}{l}\text { Temperature } \\
\text { requirement abs. } \\
\text { chiller }\end{array}$ & $90^{\circ} \mathrm{C}$ & {$[47]$} \\
\hline $\begin{array}{l}\text { Temp requirement } \\
\text { ORC }\end{array}$ & $\begin{array}{l}50-150^{\circ} \mathrm{C} \\
>250^{\circ} \mathrm{C}\end{array}$ & {$[43 ; 48]$} \\
\hline ORC & $\begin{array}{l}\eta=8.4 \%\left(50-150^{\circ} \mathrm{C}\right) \\
\eta=20 \%\left(>250^{\circ} \mathrm{C}\right)\end{array}$ & {$[13 ; 43]$} \\
\hline absorption chiller & $\mathrm{COP}=0.7$ & {$[40]$} \\
\hline compression chillers & $\mathrm{COP}=2$ & {$[26]$} \\
\hline Bio-CHP & $\begin{array}{l}\text { alpha }=0.45 \\
\eta=1\end{array}$ & {$[29-30]$} \\
\hline Coal-CHP & $\begin{array}{l}\text { alpha }=0.55 \\
\eta=0.88\end{array}$ & {$[29-30]$} \\
\hline NG-CHP & $\begin{array}{l}\text { alpha }=1.04 \\
\eta=0.9\end{array}$ & {$[29-30]$} \\
\hline Heat pump & $\mathrm{COP}=3$ & {$[29-30]$} \\
\hline Bio-HOB & $\eta=0.95$ & {$[29-30]$} \\
\hline Coal-HOB & $\eta=0.9$ & {$[29-30]$} \\
\hline NG-HOB & $\eta=0.92$ & {$[29-30]$} \\
\hline Oil-HOB & $\eta 29-30]$ \\
\hline
\end{tabular}

\section{RESULTS AND ANALYSIS}

This section first covers the system analysis of excess heat use and electricity production in the system. Thereafter, the changes on $\mathrm{CO}_{2}$ emissions will be presented and finally economic results will be given. To support the reader through Section 6, Table 4 presents a brief summary of the scenarios. For a through description of the energy market scenarios, see Table 2. The model, and hence the results, is based on the heat potential derived from a questionnaire in Gävleborg County presented in Broberg Viklund and Johansson [3]. 
Table 4 A brief summary of EMS-1 to EMS-6. Energy prices (fuel and electricity) differ between the scenarios, for a through description of the input in the six energy market scenarios see Table 2 .

\begin{tabular}{|l|l|l|l|l|l|l|}
\hline EMS & $\mathbf{1}$ & $\mathbf{2}$ & $\mathbf{3}$ & $\mathbf{4}$ & $\mathbf{5}$ & $\mathbf{6}$ \\
\hline $\begin{array}{l}\text { Marginal user of } \\
\text { biofuel }\end{array}$ & FT & FT & Coal & FT & FT & Coal \\
\hline $\begin{array}{l}\text { Build marginal } \\
\text { technology for } \\
\text { electricity } \\
\text { production }\end{array}$ & Coal & Coal & NGCC & Coal & Coal & NGCC \\
\hline DH system & $\begin{array}{l}\text { Bio- } \\
\text { HOB }\end{array}$ & $\begin{array}{l}\text { Bio- } \\
\text { HOB }\end{array}$ & $\begin{array}{l}\text { Bio- } \\
\text { HOB }\end{array}$ & $\begin{array}{l}\text { Bio- } \\
\text { CHP }\end{array}$ & $\begin{array}{l}\text { Bio- } \\
\text { CHP }\end{array}$ & $\begin{array}{l}\text { Bio- } \\
\text { CHP }\end{array}$ \\
\hline
\end{tabular}

\subsection{EXCESS HEAT USE}

In all the scenarios studied and throughout the three periods, all the available industrial excess heat is used in the system. The trade-off between using excess heat in the different measures modeled is illustrated in both Figure 2 and Figure 3. No excess heat passes through the ORC, and so no electricity is generated there. The revenue from electricity produced and sold in the ORC is not as large as the system benefits when the heat is used in the DH and DC system. All the industrial excess heat is either used in the DH system or used to generate cooling delivered in the DC system. The heat and cooling load varies throughout the year, which is illustrated with the three periods T1, T2, and T3. The available excess heat during these periods is also shown in both Figure 2 and Figure 3.

In EMS-1 to EMS-3, the excess heat is prioritized for heat deliveries in the DH system in all periods. Due to the lower heat demand in T3, not all the available excess heat is delivered to the DH system and excess heat is in this period also used for cooling production. Since the heat demand in EMS-1, EMS-2 and EMS-3 is covered with HOB no electricity are produced and sold in these scenarios. Heat use in the DH system reduces the use of fuels in the DH system and the gain from reduced use of fuels proved to exceed the gain of reduced electricity demand if the heat had been use in the DC system.

As in EMS-1 to EMS-3, the heat demand in EMS-4 to EMS-6 in period T3 is covered with excess heat. This is due to T3 being the period with the lowest electricity price, reducing the loss of revenue from sold electricity if using excess heat instead of running the CHP plants. Since there are additional excess heat resources in T3, the rest of the potential will be used in the absorption cooling.

In T1 in EMS-4 and EMS-5, all the available excess heat is used in the DH system. This period holds an intermediate level of heat and cooling load as well as electricity price and EMS-4 holds an intermediate price of biomass while EMS-5 holds a low price of biomass. The cost for fuels in the CHP plants exceeds the cost for electricity to cover the cooling demand with compression cooling and therefore (the system cost is minimized in the model) the excess heat is use in the DH system. The high electricity price in T2 in EMS-4 and EMS-5 together with the intermediate and low price for biomass results in the cooling demand being covered with excess heat, and only the surplus heat is used in the DH system. As a consequence electricity is produced in the CHP plants and sold for the high electricity price associated with this period. 
In EMS-6 during T1 and T2, the excess heat deliveries prioritize cooling production in the absorption chiller. In this scenario, the price of biomass is high and T1 holds a high electricity price while in $\mathrm{T} 2$ the price is in the middle level. The cost for electricity use to cover the cooling demand with compression cooling is higher than the cost to cover the heat demand with a bio-CHP plant combined with the revenues generated from sold electricity produced in the CHP plants.

The results show no clear pattern regarding which excess heat flows (the available excess heat flows can be seen in Table 1) should be used for the different measures. Low-temperature heat flows as well as high temperature heat flows are used for heat deliveries as well as cooling production. The temperature requirement of $\mathrm{DH}$ deliveries and for the absorption cooling is equal $\left(90^{\circ} \mathrm{C}\right.$, see Table 3$)$. The temperature requirement for ORC differs from these technologies $\left(50-150^{\circ} \mathrm{C}\right.$ and $>250^{\circ} \mathrm{C}$, see Table 3), and so if this technology had been implemented, this might have affected the heat flow distribution.

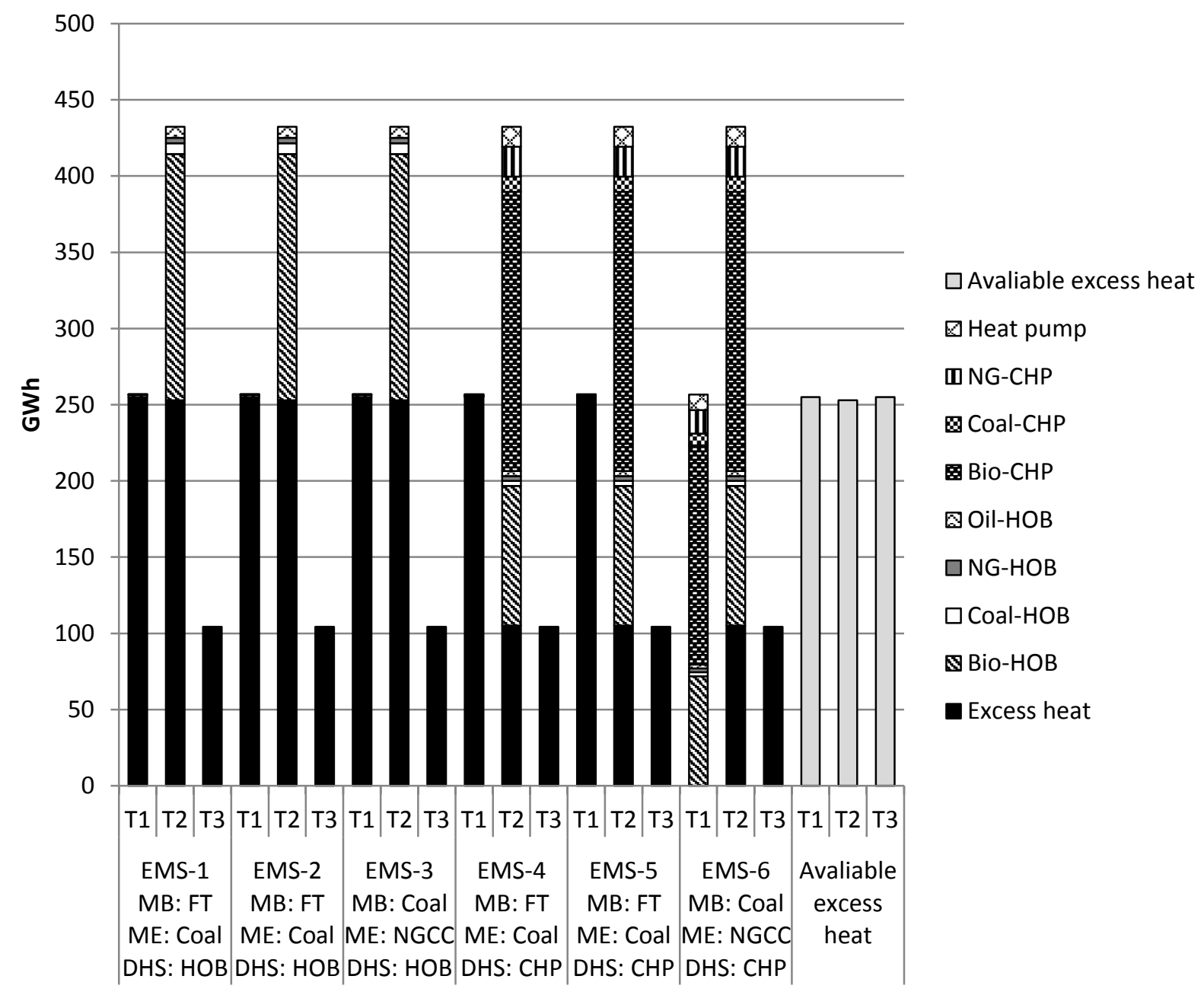

Figure 2 Recovered heat supplied in the district heating system for EMS-1 to EMS-6 divided into periods $\mathrm{T} 1, \mathrm{~T} 2$ and $\mathrm{T} 3$. $(\mathrm{MB}=$ marginal user of biomass, $\mathrm{ME}=$ build marginal technology for electricity production, DHS = district heating system). 


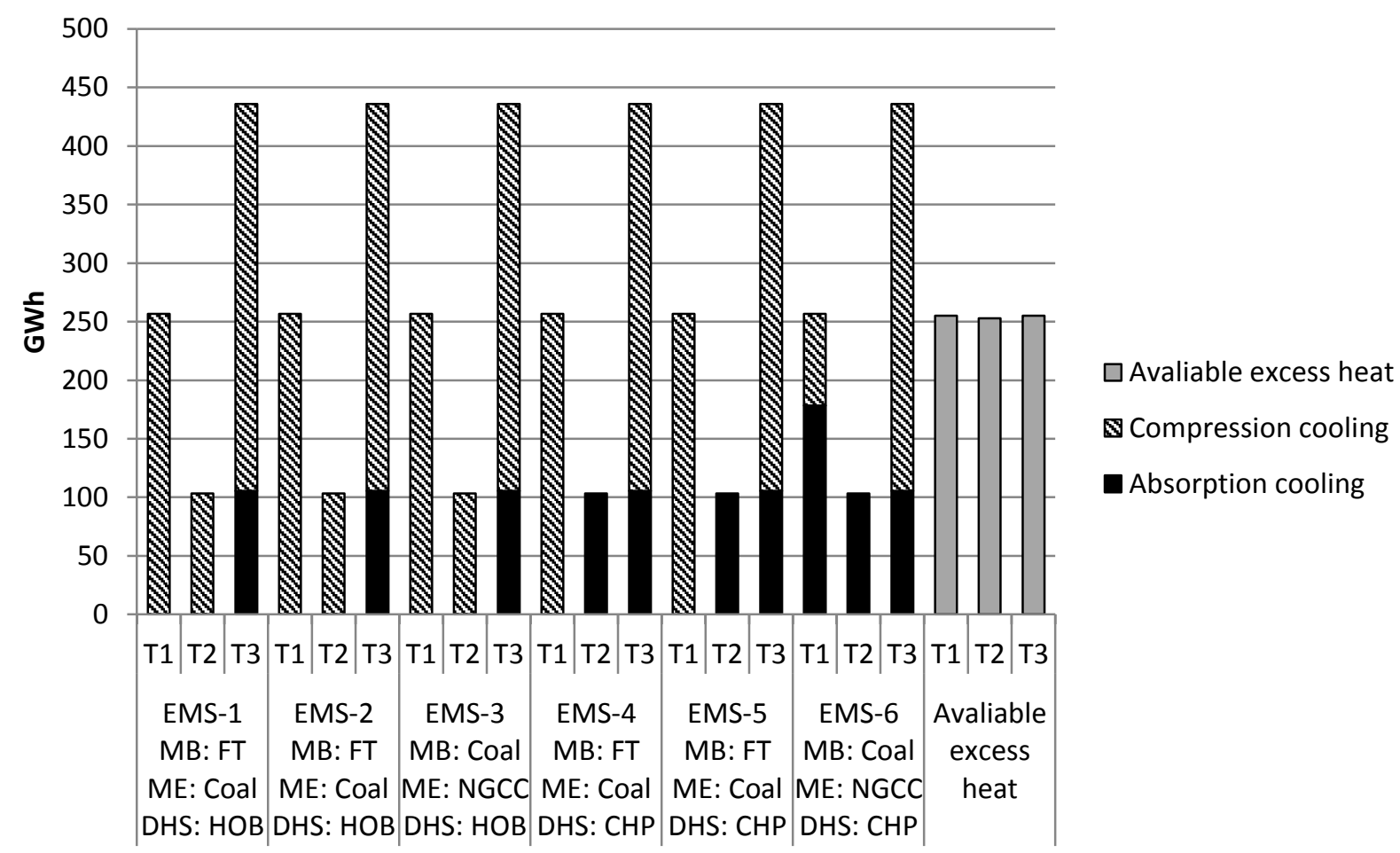

Figure 3 Cooling supply in the district cooling system for EMS-1 to EMS-6 divided into periods $\mathrm{T} 1, \mathrm{~T} 2$ and $\mathrm{T} 3$. (MB = marginal user of biomass, $\mathrm{ME}=$ build marginal technology for electricity production, DHS = district heating system).

\subsection{ELECTRICITY PRODUCED}

The amount of electricity produced in the different scenarios is shown in Figure 4. Since no excess heat passes through the ORC in neither of the scenarios and EMS-1 to EMS-3 does not have any CHP plants in the DH system, the figure only covers EMS-4 to EMS-6. 


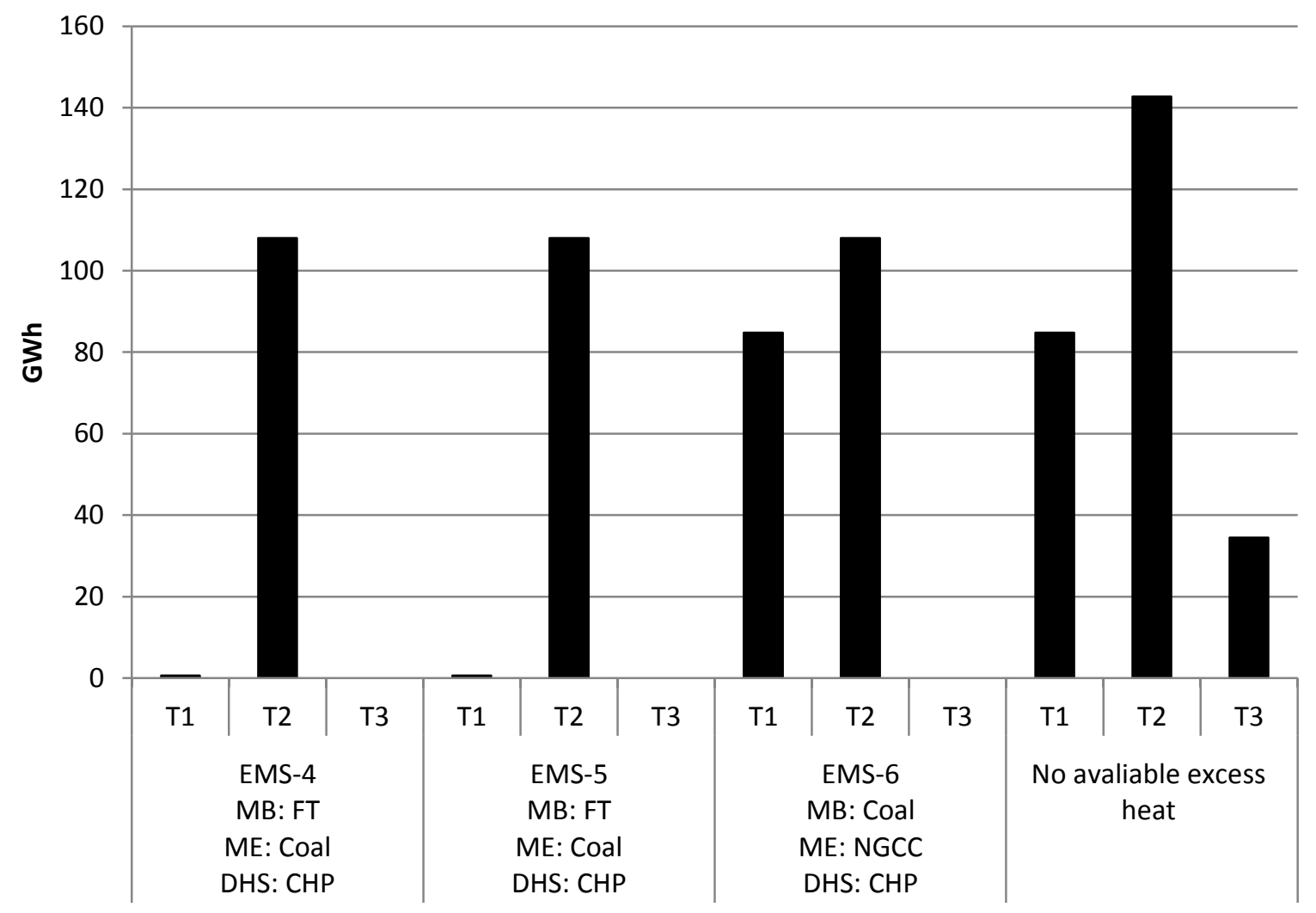

Figure 4 Electricity production, EMS-4, EMS-5, and EMS-6 divided into T1 to T3. The electricity production if no excess heat is available in the system is included in the graph. (MB = marginal user of biomass, $\mathrm{ME}=$ build marginal technology for electricity production, $\mathrm{DHS}$ $=$ district heating system).

The electricity production follows the pattern of excess heat use to cover the heat load in the system. The use of excess heat in the DH system in EMS-4 to EMS-6 leads to a decreased electricity production within the system compared to if the systems' heat load would be covered with heat from the CHP plants. Figure 4 also illustrates the electricity production (originating from the CHP plants) if no excess heat is available in the system to visualize the reduction in electricity production as a consequence of excess heat use. The highest heat load in the system is during T2. In all three scenarios, electricity is produced in this period. Even though heat is used in the DH system in this period, the available excess heat does not cover the high heat load in period T2 and hence heat must be produced in the CHP plants in this period.

\section{3 $\mathrm{CO}_{2}$ EMISSIONS EVALUATION}

The $\mathrm{CO}_{2}$ emission impact is calculated assuming the marginal emissions for electricity and biomass according to the energy market scenarios (see Section 3.3). The effect on $\mathrm{CO}_{2}$ emissions related to the change in the energy system can be seen in Figure 5. The figure shows the delta $\mathrm{CO}_{2}$ emissions compared to if no excess heat was used within the system. The use of the available industrial excess heat reduces the total $\mathrm{CO}_{2}$ emissions in all the studied scenarios. The size of reduction differs between the scenarios. 


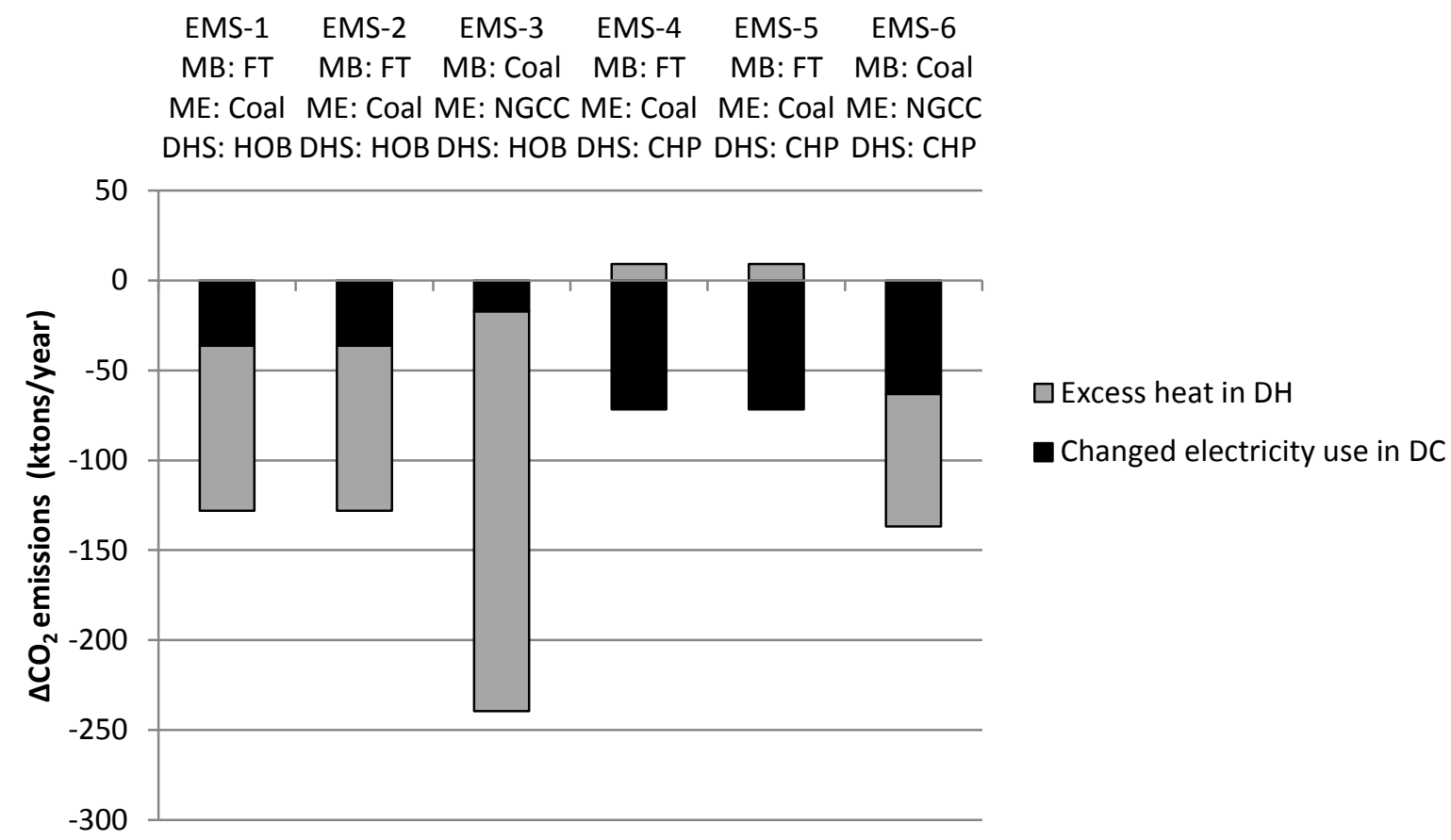

Figure 5 Carbon dioxide emission reductions in the system for EMS-1 to EMS-6. The graph illustrates the delta $\mathrm{CO}_{2}$ emissions compared to if no excess heat was used in the system. (MB $=$ marginal user of biomass, $\mathrm{ME}=$ build marginal technology for electricity production, $\mathrm{DHS}$ $=$ district heating system).

Depending on the use of excess heat, fuels, and electricity, the $\mathrm{CO}_{2}$ emissions will vary. Produced electricity within the system is assumed to replace marginal electricity and thereby an increase in electricity production will result in lower $\mathrm{CO}_{2}$ emissions. In addition, the use of excess heat in the $\mathrm{DH}$ system reduces the $\mathrm{CO}_{2}$ emissions; however, less electricity will be produced in the system than if the DH system uses CHP plants for heat production (in EMS-4 to EMS-6). The use of excess heat in the DC system reduces the need for electricity to fulfill the cooling load.

EMS-1 to EMS-3 does not include CHP plants in the DH system, and hence introducing excess heat in these scenarios does not affect the electricity production. The use of excess heat will reduce the need of fuel if used in the DH system as well as the amount of electricity if used in the DC system. The difference between EMS-1/EMS-2 and EMS-3 arises from the build marginal technology for electricity production (coal instead of NGCC) and the marginal user of biomass (biofuel production/FT production instead of co-combustion in coal power plants).

The heat production in EMS-4 to EMS-6 arises primarily from bio-CHP. The use of excess heat in these scenarios will therefore affect the electricity production. Looking at period $\mathrm{T} 1 \mathrm{in}$ EMS-4 and period T1 in EMS-5, the $\mathrm{CO}_{2}$ emissions increase, although the emissions reduce during the year overall. During these periods, the whole excess heat potential is used in the DH system, reducing the electricity production significantly. The marginal user of biofuel (co-combustion in coal power plants) and the build marginal technology for electricity production (NGCC) in EMS-6, combined with all excess heat being used in the DC system in T1 explains the higher emissions reduction in EMS-6 compared to EMS-4 and EMS-5. 


\subsection{ECONOMIC RESULTS}

Figure 6 shows the calculated annual IO for the six energy market scenarios used. The IO is positive in all scenarios and range between $14-26$ MEUR per year. The investment cost will be highly dependent on factors such as the distance to the DH or DC network, the excess heat source temperature level and the aggregation of heat flows. These costs will have to be covered by the IO.

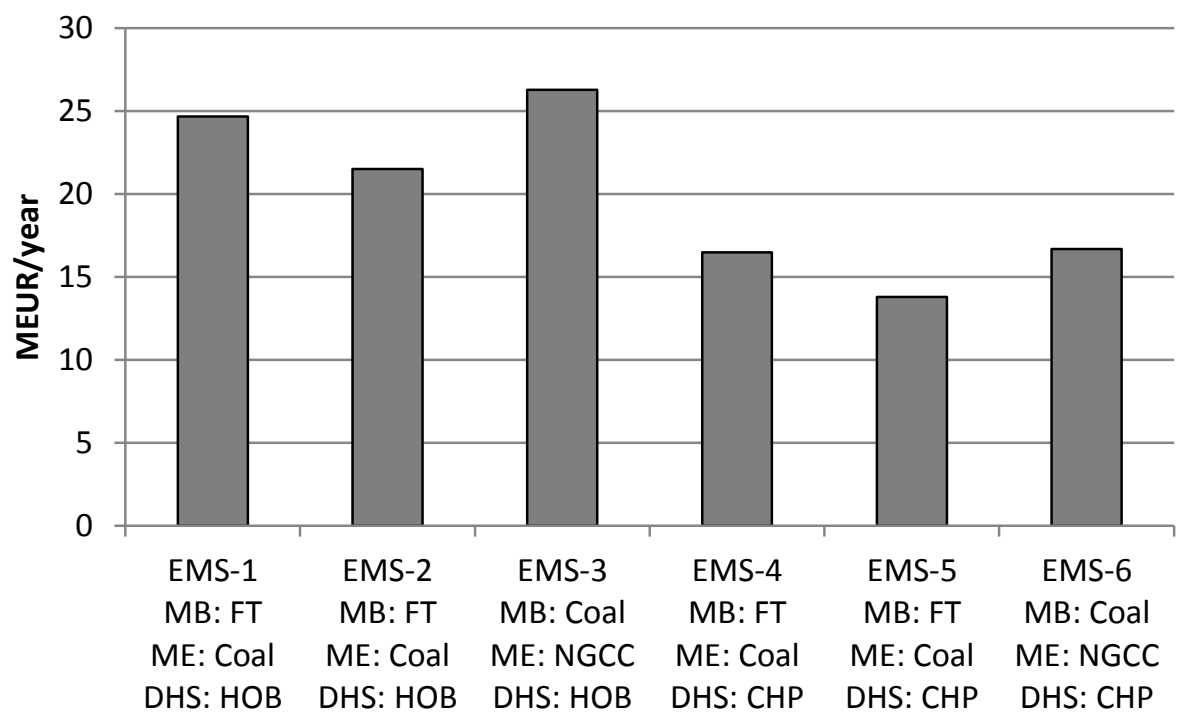

Figure 6 Annual investment opportunity for the six energy market scenarios, EMS-1 to EMS6. $(\mathrm{MB}=$ marginal user of biomass, $\mathrm{ME}=$ build marginal technology for electricity production, $\mathrm{DHS}=$ district heating system).

As can be seen in Figure 6, the economic performance of excess heat use is better in the cases where the DH system is based on bio-HOB (EMS-1 to EMS-3) than when the DH system is based on bio-CHP (EMS-4 to EMS-6). This can be explained by the fact that in the bio-CHP based systems electricity is generated in the CHP plants which in turns generate revenue, and when using excess heat the possibility to produce electricity is reduced. As can be seen in eq. (1) revenues from electricity production reduces the annual system cost and when electricity production is reduced, when excess heat is used, the right term in eq. (2) is increased and, thus, $\mathrm{IO}$ is reduced.

The results also show that the fuel and electricity prices affect the IO. In EMS-2 and EMS-5 the fuel and electricity prices are generally lower than in EMS1, EMS-3, EMS-4 and EMS-6, which reduces the IO.

\section{CONCLUDING DISCUSSION}

This study is based on the untapped excess heat potential in Gävleborg County presented in [3]. Broberg Viklund and Johansson [3] aimed at identifying the amount of untapped excess heat, i.e. the excess heat currently used is not included in the presented potential (e.g. heat delivered to a DH network) (see Table 1). Due to that the paper only covers this untapped excess heat potential combined with the response rate $(33 \%)$, the total amount of excess heat among the studied industries in the county is likely to be larger than what is reported in [3]. 
The energy systems analysis and modeling of untapped heat potentials show that it is advantageous to use the available excess heat for deliveries to the $\mathrm{DH}$ and/or DC system, independent of which of the energy market scenario that is used to analyze the system. The use of excess heat for electricity production using ORC shows that this is not the most profitable measure based on the study assumptions; the efficiency of the ORC technology (8.4-20\%) is likely too low to be a part of an optimal systems solution. Several studies investigate the economic feasibility of ORC and the authors conclude that it could be a potentially attractive investment, based on the given assumptions in those studies. However the calculated pay-back times of approximately 4-6 years may be too long for some industries. [13; 49-50] Further development of this technology may make heat driven electricity generation attractive in the future.

Access to and use of excess heat reduces the system cost since it reduces the need of fuels in the DH system and/or electricity in the DC system. In the cases where the DH system is based on CHP, excess heat use in the DH systems results in reduced electricity production. If the heat production in the $\mathrm{DH}$ system is based on $\mathrm{HOB}$, the most profitable solution is to use the heat in the DH system.

When studying the results from the scenarios where the DH system is based on CHP, the following can be inferred: A low electricity price affects the system by favoring excess heat use in the DH system since the profit to reduce the use of fuels in the heat production exceeds the profit of the otherwise produced and sold electricity and the reduced use of electricity in the DC system. A high electricity price on the other hand, favors heat use in the DC system. When the electricity price is intermediate the trend for the optimal systems solution for heat use is not that clear; however, the combination of an intermediate electricity price and a low or intermediate biofuel price favors heat use in the DH system, whereas the combination of an intermediate electricity price and a high biomass price favors heat use in the DC system.

The access to excess heat reduces not only the system cost, but also the $\mathrm{CO}_{2}$ emissions. The aggregated $\mathrm{CO}_{2}$ emissions are reduced in all the studied scenarios compared to if no excess heat was introduced and used in the system. The magnitude of emissions reduction depends on the heat use measure, that is, what the heat ultimately replaces. The $\mathrm{CO}_{2}$ emissions are reduced due to the reduced use of electricity in the DC system, and the reduced use of fuels in the DH system. Single periods (in EMS-4 and EMS-5) show an increase in $\mathrm{CO}_{2}$ emissions due to a reduced electricity production in the CHP plants. This reduction in electricity production is assumed to be covered with marginal electricity production, which increases the $\mathrm{CO}_{2}$ emissions.

Looking at the heat and cooling supply in the studied energy system (Figure 2 and Figure 3) it can be seen that the use of excess heat reduces the need for the alternative technologies to cover the heating and cooling demand (e.g. bio-HOB, bio-CHP and compression cooling). Since these alternative technologies are not used during several months of the year one may realize that the introduction of excess heat in the heating and cooling system affects the costeffectiveness of these technologies, and as a consequence the cost-effectiveness of this energy systems solution can be questioned.

Due to that the model is based on, amongst others, aggregated heat flows it is difficult to estimate the total investment cost and therefore the IO has been calculated. The presented IO is based on the annual differences in energy cost, and hence, the IO has to cover the actual technology and infrastructure investment as well as cost associated with operation and maintenance. Calculations of the IO for the studied scenarios show that the IO is dependent 
on several factors: the type of heating system and future energy market parameters. The requirements of the internal rate of return and the payback time will affect the ability of the investment to be implemented.

It is important to note that the results of this study are the outcome of the assumptions made in the model (see Section 5). The paper presents a systems study based on aggregated data, and as a result this is reflected in the assumptions used. Aggregated data is necessary when performing system studies; however input data may be problematic, e.g. the difficulty confirming the efficiency of the ORC technology. The use of scenarios, and the data associated with them also affects the outcome of this study. Consistent energy market scenarios for 2030 were used, three scenarios each for two different DH systems, to deal with difficulties in predicting future energy prices. Moreover, there are other ways to calculate e.g. the $\mathrm{CO}_{2}$ emissions consequences than the marginal approach as used in this study. Despite this, the study implies the benefits that come with excess heat use. The study contributes with knowledge regarding excess heat use, but investments in technologies for excess heat use needs to be preceded with more detailed studies to investigate practical constraints with the different applications. It is important to be aware of that the potential for excess heat use may be limited due to these practical constraints.

The heat market can be looked upon as local; therefore a Swedish mix in the heat production is used in the model. It is assumed that by 2030 there will be a functioning European electricity market, and hence a European approach has been used for the electricity market. Electricity prices are based on the prices derived from the scenario tool; however, individual firms - the firms with the sources of excess heat - may have more favorable electricity prices not taken into account in this study. Also, the impact of support for renewable electricity production, in this case in the ORC, is not investigated. In this study, the year has been divided into three periods representing the energy price fluctuations during a year. No period in the model describes the short period of the year where the heat/cooling demand peaks. Instead, average loads for three periods were modeled since it is assumed not to be profitable to invest in these measures for such a short period as the peak periods.

\section{ACKNOWLEDGEMENT}

This work was carried out under the auspices of the Energy Systems Programme, funded by the Swedish Energy Agency. The authors would like to thank the reviewers for their help with improving the quality of this paper.

\section{REFERENCE}

[1] EC (European Comission). Communication from the Comission, Europe 2020. A strategy for smart, sustainable and inclusive growth, 2010, Brussels.

[2] EC (European Comission).Directive of the European Parliament and of the Council on energy efficiency, 2012, 2012/27/EU.

[3] Broberg Viklund, S., Johansson, M. T. Technologies for utilization of industrial excess heat - potentials for energy recovery and $\mathrm{CO}_{2}$ emission reduction. Energy Conversion and Management 2014;77:369-379.

[4] Gou, X., Xiao, H., Yang, S. Modeling, experimental study and optimazation on lowtemperature waste heat thermoelectric generator system. Applied Energy 2010;87:3131-3136.

[5] Quoilin, S., Aumann, R., Grill, A., Schuster, A., Lemort, V., Spliethoff, H. Dynamic modeling and optimal control strategy of waste heat recovery Organic Rankine Cycles 2011;88:2183-2190. 
[6] Rezaie B. and Rosen M.A. District heating and cooling: Review of technology and potential enhancements. Applied Energy 2011;93: 2-10.

[7] Thekdi, A. and Belt, C., 2011. Waste heat reduction and recovery options for metal industry. Energy Technology 2011. DOI: 10.1002/9781118061886.ch2

[8] Swedish District Heating Association, 2010. Excess Heat 2010. [Överskottsvärme 2010] Swedish District Heating Association, Sweden. [In Swedish]

[9] Swedish District Heating Association. Fuel and production 2011 [Bränsle och produktion 2011]. Excel sheet accessed through personal communication. Stockholm, Sweden, Swedish District Heating Association. [in Swedish]

[10] Ammar, Y., Joyce, S., Norman, R., Wang, Y., Roskilly, A.P. Low grade thermal energy sources and uses from the process industry in the UK. Applied Energy 2012;89(1):3-20

[11] Campana, F., Bianchi, M., Branchini, L., De Peretto, A., Baresi, M., Fermi, A., Rossetti, N., Vescovo, R. ORC waste heat recovery in European energy intensive industries: Energy and GHG savings. Energy Conversion and Management 2013;76:244-252.

[12] Chua, K.J., Chou, S.K., Yang, W.M. Advances in heat pump systems: A review. Applied Energy 2010;87(12):3611-3624

[13] Johansson, M.T., Söderström, M., 2012. Electricity generation from low temperature industrial excess heat - an opportunity for the steel industry. Energy Efficiency 2013, DOI:10.1007/s12053-013-9218-6

[14] Jönsson, J., Svensson, I.L., Berntsson, T., Moshfegh, B. Excess heat from Kraft pulp mills: Trade-offs between internal and external use in the case of Sweden - Part 2: Results for future energy market scenarios. Energy Policy 2008;36(11):4186-4197.

[15] Miró, L., Navarro, M.E., Suresh, P., Gil, A., Fernández, A.I., Cabeza, L.F. Experimental characterization of a solid industrial by-product as material for high temperature sensible thermal energy storage (TES). Applied Energy 2014;113:1261-1268

[16] Persson, U., Werner, S. District heating in sequential energy supply, Applied Energy 2012;95:123-131

[17] Svensson, I.L., Jönsson, J., Berntsson, T., Moshfegh, B. Excess heat from Kraft pulp mills: Trade-offs between internal and external use in the case of Sweden - Part 1: Methodology. Energy Policy 2008;36(11):4178 - 4185.

[18] Wang, W., Guo, S., Li, H., Yan, J., Zhao, J., Li, X., Ding, J. Experimental study on the direct/indirect contact energy storage container in mobilized thermal energy system (M-TES). Applied Energy 2014;119:181-189

[19] Broberg, S., Backlund, S., Karlsson, M., Thollander, P. Industrial excess heat deliveries to Swedish district ehating networks: Drop it like it's hot. Energy Policy 2012;51:332 - 339 .

[20] Cronholm, L.Å., Grönkvist, S., Saxe, M. Excess heat from industrial firms and heat recovery premises [Spillvärme från industrier och lokaler]. Report 2009:12, 2009, The Swedish District Heating Association.

[21] Karlsson, M. The MIND method: A decision support for optimization of industrial energy systems - Principles and case studies. Applied Energy 2011;88:577 - 589.

[22] The Swedish Government through the Ministry of the Environment, 1998. Constitution on environmental hazardous activities and health, 1998:899.

[23] Statistics Sweden. Energy. [Energi] 2014. Available from: www.scb.se, 2014 [In Swedish]

[24] RUS, 2014. National emission database - County report Gävleborg [nationella emissionsdatabasen - Länsrapport Gävleborg] Excel sheet accessed at: projektwebbar.lansstyrelsen.se/rus/Sv/statistik-och-data/, 2014-02-25 [in Swedish]

[25] Karlsson, M., Söderström, M. Sensitivity analysis of investments in the pulp and paper industry - On investments in the chemical recovery cycle at the board mill. International Journal of Energy Research 2002;26:1253 - 1267. 
[26] Svensson, I.L., Moshfegh, B. System analysis in a European perspective of new industrial cooling supply in a CHP system. Applied Energy 2011;88:5164 - 5172.

[27] Thollander, P., Mardan, N., Karlsson, M. Optimization as investment decision support in a Swedish medium-sized iron foundry - A move beyond traditional energy auditing. Applied Energy 2009;86:433-440.

[28] Wolf, A., Karlsson, M. Evaluating the environmental benefits of industrial symbiosis: discussion and demonstration of a new approach. Progress in Industrial Ecology - An International Journal 2008;5:502 - 517.

[29] Axelsson, E., Harvey, S., Berntsson, T., 2009. A tool for creating energy market scenarios for evaluation of investments in energy intensive industry. Energy 2009;34(12):2069 - 2074.

[30] Axelsson, E., Harvey, S., 2010. Scenarios for assessing profitability and carbon balances of energy investments in industry - Pathways to sustainable European energy systems. AGS Pathways report 2010:EU1. Gothenburg: AGS, The alliance for global sustainability; 2010.

[31] IEA (International Energy Agency). World Energy Outlook 2011. 2011.

[32] Dotzauer, E. Greenhouse gas emissions from power generation and consumption in a nordic perspective. Energy Policy 2010;38:701-704.

[33] Sjödin, J., Grönkvist, S. Emissions accounting for use and supply of electricity in the Nordic market. Energy Policy 2004;32:1555-1564.

[34] Swedish District Heating Association. Fuelfile-district_heating-2012 [Bränslefilfjärrvärme-2012]. Excel-sheet. 2014. Avaliable at: www.svenskfjarrvarme.se, 2014-02-13 [In Swedish]

[35] Bengtsson, C., Karlsson, M., Berntsson, T., Söderström, M. Co-cordination of pich technology and the MIND method - applied to a Swedish board mill. Applied Thermal Engineering 2002;22:133-144.

[36] Heyne, S., Harvey, S. Consistent assessment of the energy and economic performance of second generation biofuel production processes using energy market scenarios. Applied Energy 2013;101:203-2012.

[37] Wetterlund, E., Pettersson, K., Harvey, S. Systems-analysis of integrating biomass gasification with pulp and paper production - Effects on economic performance, $\mathrm{CO}_{2}$ emissions and energy use. Energy 2011;36:932-941.

[38] Ericsson, K. Introduction and development of the Swedish district heating system Critical factors learned. Report as part of the IEE project "Policy development for improving RES-H/C penetration in European member States", 2009, Lund University, Lund, Sweden.

[39] Lindmark, S. The role of absorption cooling for reaching sustainable energy systems. Licentiate thesis, 2005, Royal Institute of Technology, Stockholm, Sweden.

[40] Rystrand, M., Martin, V., Westermark, M., 2004. Heat driven cooling [Värmedriven kyla]. FOU 2004:112. The Swedish District Heating Association, Stockholm, Sweden. [In Swedish]

[41] Asp, B., Wiklund, M., Dahl, J. Utilization of excess energy from the steel industry for electricity production: an effective utilization of resources for electricity production [Användning av stålindustrins restenergier för elproduktion: Ett effektivt resursutnyttjande för elproduktion]. Report no. JK 98400, 2008. Jernkontoret, Stockholm, Sweden. [In Swedish]

[42] Law, R., Harvey, A., Reay, D., 2012. Opportunities for low-grade heat recovery in the UK food processing industry. Applied Thermal Engineering. Doi:10.1016/j.applthermaleng.2012.03.024.

[43] Vélez, F., Gegovia, J.J., Martín, M.C., Antolín, G., Chejne, F., Quijano, A. A technical, economical and market review of organic Rankine cycles for the conversion of low-grade heat for power generation. Renewable and Sustainable Energy Reviews 2012;16:4175 - 4189. 
[44] Karlsson, M., Gebremedhin, A., Klugman, S., Henning, D., Moshfegh, B. Regional energy system optimization - Potential for a regional heat market. Applied Energy 2009;86:441 - 451 .

[45] Swedish District Heating Association. Taxes and policy instruments. [Skatter och styrmedel] Avaliable at: www.svenskfjarrvarme.se, 2013. [In Swedish]

[46] Nord Pool Spot. Avaliable at: www.nordpoolspot.com, 2012.

[47] Srikhirin, P., Aphornratana, S., Chungpaibulpatana, S. A review of absorption refrigeration technologies. Renewable and Sustainable Energy reviews 2001;5:343 - 372.

[48] Opcon Energy Systems, 2012. Avaliable at: www.opcon.se, 2012-12-10

[49] Walsh, C., Thornley, P. The environmental impact and economic feasibility of introducing an Organic Rankine Cykle to recover low grade heat during the production of metallurgical coke. Journal of Cleaner Production 2012;34:29-37

[50] Walsh, C., Thornley, P. A comparison of two low grade recovery options. Applied Thermal Engineering 2013;53:210-216 